\title{
Biological Traits and the Transfer of Persistent Organic Pollutants through River Food Webs
}

\author{
Fredric M. Windsor, ${ }^{*}, \dagger,+, \| \odot$ M. Glória Pereira, ${ }^{\S}$ Charles R. Tyler, ${ }^{*}$ and Stephen J. Ormerod ${ }^{\dagger \odot}$ \\ ${ }^{\dagger}$ School of Biosciences, Cardiff University, Cardiff, South Glamorgan CF10 3AX, U.K. \\ ${ }^{\ddagger}$ Biosciences, University of Exeter, Exeter, Devon EX4 4QD, U.K. \\ ${ }^{\S}$ Centre for Ecology and Hydrology, Lancaster, Lancashire LA1 4AP, U.K.
}

Supporting Information

\begin{abstract}
Freshwater organisms remain at risk from bioaccumulation and biomagnification of persistent organic pollutants (POPs), but factors affecting their transfer through food webs are poorly understood. Here, we investigate transfer pathways of polychlorinated biphenyls, polybrominated diphenyl ethers, and organochlorine through a river food web, assessing the distribution and flux between basal resources $(n$ $=3)$, macroinvertebrates $(n=22)$, and fish $(n=1)$. We investigate the effects of biological traits on the observed patterns and use trait-based models to predict POP bioaccumulation. Transfer pathways differed among POPs and traits such as habitat affinity, feeding behavior, and body size explained some variation in POP burdens between organisms.
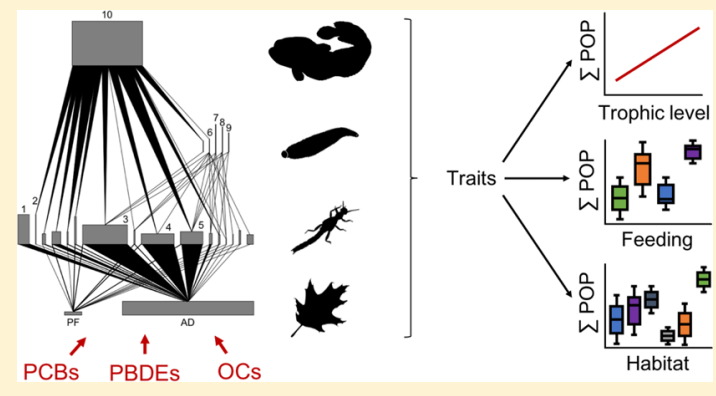

Trait-based models indicated that relationships between POPs, trophic transfers, and traits were relatively well conserved across a wider array of river food webs. Although providing more consistent predictions of POP bioaccumulation than steady-state models, variability in bioaccumulation across food webs limited the accuracy of trait-model predictions. As some of the first data to illustrate how ecological processes alter the flux of pollutants through river food webs, these results reveal important links between POPs and contrasting energetic pathways. These data also show the utility of trait-based methods in the assessment of persistent contaminants, but further field validations are required.
\end{abstract}

\section{INTRODUCTION}

Xenobiotic pollutants-chemicals which do not occur naturally in the environment-are distributed widely across the Earth's freshwater ecosystems. ${ }^{1}$ These pollutants are particularly hazardous to individual organisms and have impacts through a diverse array of pathways, including endocrine disruption. ${ }^{2}$ Multiple taxonomic groups are at risk, including microbes, ${ }^{3}$ benthic invertebrates, ${ }^{4}$ fish, ${ }^{5}$ and aquatic birds. $^{6}$ In natural systems, these negative effects can transcend levels of biological organization to affect populations, communities, and ecosystems with consequences for ecosystem services and the functioning of the socio-biological system. ${ }^{2,7}$

Legacy organic chemicals are a group of xenobiotic pollutants that have largely been withdrawn from legal use, but remain widespread across freshwater ecosystems either because of their persistence or low-level recirculation from discarded materials, landfill, or local illicit use. ${ }^{8}$ Generally referred to as persistent organic pollutants (POPs), across Europe, these chemicals often occur at relatively low environmental concentrations, ${ }^{9}$ but their hydrophobic and lipophilic nature enables accumulation in freshwater organisms (invertebrates, fish, and mammals) and significant magnification across the trophic levels of aquatic food webs. ${ }^{10-15}$ Although the environmental concentrations of these chemicals might suggest a relatively low potential for ecological risks, long-term exposure, assimilation, and subsequent accumulation and/or magnification of persistent contaminants could represent a continued threat to individual organisms, population, and communities across the wider freshwater ecosystem. ${ }^{2}$

Although the bioaccumulation and biomagnification of POPs are key to understanding ecological risks from persistent and hydrophobic chemicals, factors affecting transfer processes and cascading ecological effects across trophic levels are poorly understood. $^{16,17}$ Existing research suggests that chemical characteristics, organism biology, and environmental characteristics might interact to influence the distribution and concentrations of POPs in aquatic and terrestrial food webs, ${ }^{12,13,18}$ with the chemical structure and concentration particularly important. ${ }^{15,19}$ The food web structure might also affect POP behavior, but much of the existing work has involved relatively simple ecosystems with restricted taxonomic or functional diversity and limited trophic interactions. Thus, although the general principle of bioaccumulation and trophic magnification of persistent pollutants is well established, ${ }^{13}$ there is limited knowledge of how complex, multilayer trophic

Received: September 30, 2019

Revised: October 21, 2019

Accepted: October 24, 2019

Published: October 24, 2019 
interactions affect POP transfers. This includes significant gaps in understanding how persistent organic contaminants might enter and pervade river food webs linked to basal resources arising from autochthony (i.e., in-river primary production) or allochthony (i.e., matter such as leaf litter originating from the riparian zone or catchment). These two resources contribute significantly to carbon and energy fluxes throughout freshwater ecosystems and are fundamental to their functioning. ${ }^{20}$ Any change in the transfer of energy from basal resources has the potential to affect organism exposure to contaminants across trophic levels.

Moreover, insights from food webs and biological trait analysis might also improve understanding of POP fluxes through ecosystems. Trait analysis has expanded generally in freshwater ecology and has been applied to an increasing array of problems. ${ }^{21}$ Although experimental studies have assessed the influence of biological traits on the accumulation of xenobiotic pollutants within the tissues of aquatic organisms, ${ }^{22-25}$ the primary focus has been on physiological traits (e.g., size and growth) in just a small number of organisms from individual taxonomic groups. In natural systems, however, trait diversity is large ${ }^{26}$ and influences several processes through variations in (i) morphological and physiological traits, including biomass, mouthpart morphology, and life-cycle duration; (ii) ecological traits, regulating events, or processes, including factors such as time of emergence, growth rate, and dispersal mechanisms; and (iii) behavioral traits, relating to the specific activities of the organism, for example, feeding and habitat preferences. All might affect the transfer and effects of POPs in freshwater communities. $^{2}$

In this study, we aimed to assess transfer pathways of persistent pollutants (polychlorinated biphenyls [PCBs], polybrominated diphenyl ethers [PBDEs], and organochlorines [OCs]) through river food webs while also investigating the influence of biological traits on POP bioaccumulation across different aquatic taxa. Our focus on these legacy pollutants reflects their value as model substances whose distribution and behavior are sufficiently well understood to aid in the development of methods for understanding the flux of compounds through food webs. We quantified POP body burdens and trophic interactions across a river food web in South Wales (United Kingdom) and used relationships among trophic transfers, biological traits, and contaminant data to develop novel, trait-based models to estimate POP bioaccumulation across eight further UK river food webs. By comparing predictions from trait-based models and steadystate equations with direct measurements of bioaccumulation for invertebrate taxa, we tested the applicability of trait-based methods for field assessments of environmental pollution. We hypothesized that

1. The transfer of POPs through food webs occurs alongside the flux of energy associated with different aquatic resources

2. Variation in bioaccumulation and biomagnification of POPs in food webs is related to biological traits

3. Trait-based models suitably predict the bioaccumulation of POPs across multiple food webs.

\section{METHODS AND MATERIALS}

2.1. Sample Site and the T1 Food Web. The analysis of bioaccumulation, biomagnification, and trophic transfer of persistent pollutants through a river food web focused on a 20 $\mathrm{m}$ stretch downstream of the Cynon Valley Wastewater Treatment Works (WwTWs) discharge into the River Taff, South Wales $\left(51^{\circ} 37^{\prime} 41.8^{\prime \prime} \mathrm{N}, 3^{\circ} 19^{\prime} 45.4^{\prime \prime} \mathrm{W}\right)$ (T1; Figure 1).

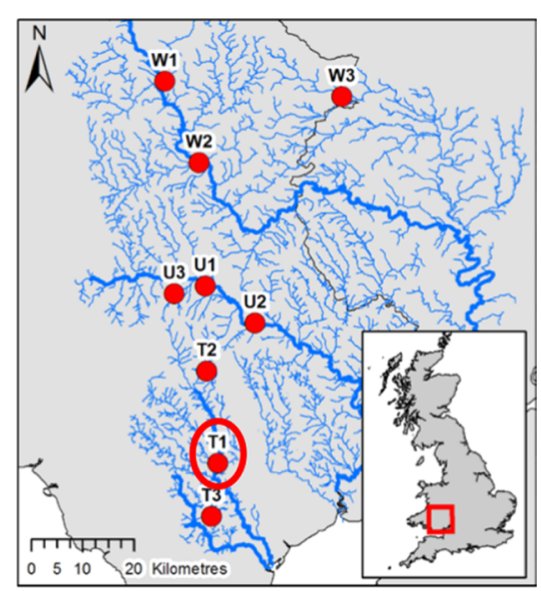

Figure 1. Location of the $\mathrm{T} 1$ sample site. $\mathrm{T} 1$ is part of a wider network of sites across South Wales which are used here for the validation of trait-models.

This facility receives wastewater from the Rhondda-Cynon Valleys (approx 63000 people) and involves primary and secondary treatment, consisting of settlement, mechanical filtering, and biological processing using percolating filter beds. The surrounding catchment is highly urbanized ( 20\%) and contains a range of pollution sources, including combined sewer overflows, storm drains, and road runoff drains, all of which have previously been shown to contribute to anthropogenic pollution loads in the Taff river system. ${ }^{27}$ The diversity of discharges and presence of legacy pollutants in benthic sediments and biota at this location make it suitable to assess pollutant transfer through the food web-which consists of a range of invertebrates and fish taxa that are representative of other hill streams recovering from past insanitary pollution. ${ }^{28,29}$

Samples were collected from 26 components of the river food web at T1 (May-August 2017) including basal resources ( $n=3$; microbial biofilm, macrophytes, and sediment-bound allochthonous detritus), invertebrate taxa $(n=21)$, and benthic fish $(n=1)$. All the samples were collected under consultation and with license from Natural Resources Wales (see Table 1 for taxonomic details). Methods varied with the sample type. For basal resources, we amalgamated sediment grab samples $(2 \mathrm{~g})$ and biofilm scrapes $\left(4 \mathrm{~cm}^{2}\right)$. Composite samples of whole organisms were used for invertebrate taxa (5-200 individuals per taxon), and composite samples of livers were used for fish ( $n=5$ individuals). We used fish livers as this organ provides a short-term store of dietary lipids, ${ }^{30}$ thus allowing evaluation of the trophic transfers of POPs from prey items. $^{31}$ Although POP concentrations in liver tissue are generally higher than those in other fish tissues, they reflect variation in POP concentrations in other tissues and among individuals. $^{32,33}$ Approximately, 1-2 $\mathrm{g}$ of each sample was collected and stored at $-80{ }^{\circ} \mathrm{C}$ in rinsed glass vials (hexane/ acetone; 1:1, v/v) until analysis (see Appendix S2 for detailed methods). 
Table 1. Concentrations of POPs in the T1 River Food Web

\begin{tabular}{|c|c|c|c|c|c|c|}
\hline \multirow[b]{2}{*}{ sample } & \multirow[b]{2}{*}{ trophic level $^{a}$} & \multirow[b]{2}{*}{ group } & \multirow[b]{2}{*}{ lipid (\%) } & \multicolumn{3}{|c|}{ concentration $\left(\mathrm{ng} \mathrm{g}^{-1} \mathrm{ww}\right)^{b}$} \\
\hline & & & & $\sum$ PBDEs & $\sum \mathrm{PCBs}$ & $\sum \mathrm{OCs}$ \\
\hline sediment $^{c}$ & 1.00 & resource & 0.00 & 0.27 & 2.73 & 7.53 \\
\hline Fontinalis spp. & 1.00 & resource & 0.02 & ND & 18.30 & 1.95 \\
\hline microbial biofilm & 1.00 & resource & 0.02 & 1.97 & 2.66 & 0.96 \\
\hline Asellus spp. & 2.00 & gatherer & 0.06 & 0.54 & ND & 1.56 \\
\hline Leuctra spp. & 2.00 & shredder & 0.09 & 1.10 & 12.24 & 7.68 \\
\hline Rhithrogena semicolorata & 2.00 & grazer & 0.15 & 2.03 & $\mathrm{ND}$ & 6.70 \\
\hline Caenis spp. & 2.00 & gatherer & 0.06 & 1.22 & $\mathrm{ND}$ & 6.92 \\
\hline Naididae & 2.00 & gatherer & 0.11 & 1.34 & $\mathrm{ND}$ & 2.87 \\
\hline Ecdyonurus spp. & 2.00 & grazer & 0.15 & 1.19 & 1.70 & 2.54 \\
\hline Baetis spp. & 2.00 & grazer & 0.15 & 3.64 & 0.56 & 4.86 \\
\hline Radix spp. & 2.00 & grazer & 0.05 & 1.35 & 4.40 & 6.30 \\
\hline Heptagenia spp. & 2.00 & grazer & 0.03 & 1.65 & 3.81 & 2.40 \\
\hline Eiseniella tetraedra & 2.00 & gatherer & 0.09 & 2.00 & 11.87 & 6.09 \\
\hline Lepidostoma hirtum & 2.00 & gatherer & 0.15 & 1.36 & ND & 24.28 \\
\hline Simuliidae & 5.20 & filterer & 0.08 & 1.12 & 0.66 & 0.36 \\
\hline Serratella ignita & 5.24 & grazer & 0.18 & 1.78 & 1.18 & 7.09 \\
\hline Sericostoma personatum & 7.60 & gatherer & 0.32 & 9.82 & 1.30 & 90.98 \\
\hline Gammarus pulex & 8.06 & shredder & 0.04 & 1.60 & 0.36 & 5.36 \\
\hline Hydropsyche spp. & 8.69 & filterer & 0.11 & 7.60 & 1.39 & 55.93 \\
\hline Polycelis spp. & 8.77 & predator & 0.39 & 8.29 & 1.65 & 127.94 \\
\hline Platambus maculatus & 9.44 & predator & 0.05 & 6.18 & 11.24 & 11.58 \\
\hline Rhyacophila dorsalis & 9.98 & predator & 0.14 & 1.67 & $\mathrm{ND}$ & 22.09 \\
\hline Polycentropus spp. & 10.14 & predator & 0.19 & 1.89 & ND & 27.19 \\
\hline E. octoculata & 10.80 & predator & 0.03 & 3.68 & 8.15 & 5.90 \\
\hline C. gobio & 11.09 & predator & 0.50 & 32.70 & 78.60 & 45.84 \\
\hline
\end{tabular}

${ }^{a}$ Chain-averaged trophic level (see Table 2 for prey-averaged values). ${ }^{b} \mathrm{ND}=$ not detected (below the limits of detection). ${ }^{c}$ Organic matter content was $0.04 \%$.

\section{CHEMICAL ANALYSES}

Environmental samples were analyzed at the Centre for Ecology and Hydrology (CEH, Lancaster) for a range of contaminants (OCs: $p, p^{\prime}$-DDT, $p, p^{\prime}$-DDE, and $p, p^{\prime}$-DDD [TDE], dieldrin [HEOD], $\alpha$ - and $\gamma$-hexachlorocyclohexane $[\mathrm{HCH}]$, and hexachlorobenzene $[\mathrm{HCB}] ; 36 \mathrm{PCB}$ congeners; and 23 PBDE congeners). Samples (0.5-2 g) were thawed, weighed accurately, ground with sand, dried with anhydrous sodium sulfate, spiked with internal recovery standards $\left({ }^{13} \mathrm{C}\right.$ OCs, ${ }^{13} \mathrm{C}$ PCBs, and ${ }^{13} \mathrm{C}$ PBDEs), and Soxhlet-extracted with dichloromethane for $16 \mathrm{~h}$. A small proportion of the extract was subsampled and evaporated to zero volume under $\mathrm{N}$, and the lipid content was then determined gravimetrically. The remaining extract was subsequently cleaned using automated size exclusion chromatography followed by solid phase extraction through an alumina glass column packed with pretreated alumina $\left(12 \mathrm{~h}\right.$ at $\left.550{ }^{\circ} \mathrm{C}\right)$ that was deactivated using deionized water $5 \%(\mathrm{w} / \mathrm{w})$. The extract was divided into two: one fraction was spiked with internal standards $\left({ }^{13} \mathrm{C}\right.$ OCs and ${ }^{13} \mathrm{C}$ PCBs) for OCs and PCBs, and ${ }^{13} \mathrm{C}$ PBDEs for the PBDEs analyses. An aliquot of the extract was injected into the gas chromatograph-mass spectrometer (Agilent, Wokingham, $\mathrm{UK}$ ) using a $50 \mathrm{~m}$ (OCs and PCBs) or $25 \mathrm{~m}$ (PBDEs) HT8 column $(0.22 \mathrm{~mm}$ internal diameter and $0.25 \mu \mathrm{m}$ film thickness; SGE, Milton Keynes, UK) and programmable temperature vaporization inlet using different methods for $\mathrm{OC} / \mathrm{PCB}$ and PBDEs. Injector temperature was $250{ }^{\circ} \mathrm{C}$, and helium was used as the gas carrier $\left(2.0 \mathrm{~mL} \mathrm{~min}^{-1}\right)$. An isothermal temperature regime was programmed at $50{ }^{\circ} \mathrm{C}$ for 2 min, then ramped at $45{ }^{\circ} \mathrm{C} \min ^{-1}$ to $200{ }^{\circ} \mathrm{C}, 1.5{ }^{\circ} \mathrm{C} \min ^{-1}$ to
$240{ }^{\circ} \mathrm{C}, 2{ }^{\circ} \mathrm{C} \min ^{-1}$ to $285{ }^{\circ} \mathrm{C}, 50{ }^{\circ} \mathrm{C} \mathrm{min}^{-1}$ to $325^{\circ} \mathrm{C}$, and $350{ }^{\circ} \mathrm{C}$ for $10 \mathrm{~min}$. Compounds were in the electron ionization mode. The internal standard method was used to quantify residues and calibration curves of commercially available standards for PCBs and OCs (Greyhound Ltd, Birkenhead, UK), and PBDEs (LGC Ltd., Teddington, UK). A series of procedural blanks were concurrently run, and samples were corrected based on recovery spikes. Recovery values were relatively consistent across all the sample media and all the compounds (85.8-103.9\%). The detection limits for analyses averaged $0.04-0.11 \mathrm{ng} \mathrm{g}^{-1}$ wet weight for all the PBDE and PCB congeners and OC compounds (Appendix S2).

Our metrics and concentrations are reported using wet weights (ww) for several reasons. First, for samples with low lipid contents, normalization produces unreliable results, with unfeasible concentrations (e.g., >6000 $\mathrm{ng} \mathrm{g}^{-1}$ lipid weight for invertebrate taxa). This reflects poor performance of gravimetric lipid calculations for samples with $<1 \%$ lipid concentrations. ${ }^{34}$ Second, there are arguments against lipid normalization under certain circumstances, such as here, where there is marked variation in the relationship between the lipid content, trophic level, and chemical concentrations. ${ }^{35}$ Third, it is erroneous to presume that chemicals partition only to tissue lipids in organisms, ${ }^{36}$ and although hydrophobic contaminants bind to lipids, not all the contaminants will be solely associated with these compounds. fourth, wet weight concentrations are used in both bioaccumulation models and environmental risk assessments. $^{37-39}$ We also use wet weight for sediments because of the relatively low variation in the particulate organic matter content across samples (0.04-0.06\%). 
3.1. Quantitative Food Web Construction. To construct a quantitative network for the food web at $\mathrm{T} 1$ and to act as a basis for understanding pollutant flux, we used the trophic basis of production. ${ }^{40}$ In outline, this uses secondary production estimates, while food web links are expressed as the flow of biomass from resources to consumers based on dietary information and estimates of secondary production that form the basis for energy flux (see Appendix S1). For macroinvertebrates, taxon-level secondary production (mg $\mathrm{m}^{-2} \mathrm{yr}^{-1}$ ) estimates were derived from monthly samples over 2016-2017 $(n=36)$ in which individuals were identified to the lowest practical taxonomic unit (usually species or genus), counted, and biomass derived from the head width or body length measurement to the nearest $0.1 \mathrm{~mm}(n=9921)$ using a Nikon SMZ800N stereomicroscope (Nikon, Tokyo, Japan), with a Lumenera Infinity 1-1M camera (Lumenera, Ontario, Canada) and visual analysis software (Infinity Analyse, version 6.5.4). Individual biomass ( $\mathrm{mg}$ dry weight) was then calculated following published length-mass relationships, ${ }^{41,42}$ and secondary production was calculated using the size-frequency method. ${ }^{43}$ For rare taxa $(n<5)$, production was estimated using the production/biomass $(\mathrm{P} / \mathrm{B})$ value for the most closely related taxa. Fish secondary production could not be directly estimated, and instead we used a $\mathrm{P} / \mathrm{B}$ ratio (2.00) derived from the existing literature ${ }^{44}$ coupled with an estimate of biomass ( $\mathrm{g}$ $\mathrm{m}^{-2}$ ) generated from an electrofishing survey during July 2017, under license from Natural Resources Wales.

Trophic links between organisms were derived from gut dissection of individual macroinvertebrates $(n=545)$ and fish $(n=15)$ in which the digestive tract of each individual was removed and relative proportions of prey items were enumerated using a gridded graticule. Where possible, the organic material was identified as either plant fragments (and other allochthonous detritus) or microbial biofilms (polysaccharide chains, diatoms, algae, and other aquatic primary producers). We calculated a mean value of the proportion of resources utilized for each taxon, including both basal resources and other invertebrates. These proportions were then used in conjunction with the trophic basis of the production method to quantify food webs. ${ }^{40}$ Based on data, the total flux of biomass to consumers (consumption) for each taxon could be separated among resources from (i) microbial biofilms (autochthonous) or (ii) detritus, organic matter, and plant fragments (allochthonous).

The trophic level of each component of the quantitative food web $(n=26)$ was calculated based on invertebrate community data and modeled links across the wider food web, which comprised 71 taxa (see Windsor et al. ${ }^{29}$ ). Trophic levels were chain-averaged ( 1 plus the weighted average of the chain length of paths from the organism to the basal resources), where weights are the flux of energy and materials ${ }^{45}$ to allow for extrapolation across river food webs. We also report a more common metric, prey-averaged trophic level ( 1 plus the mean trophic level of the consumer's resources) throughout the Results section.

3.2. Statistical Analyses. Data analysis used " $R$ " statistical software (version 3.4.0). ${ }^{46}$ Values for PCBs, PBDEs, and OCs below the detection limits were noted throughout as not detected (ND), and for statistical analyses, a value equal to the minimum detection limit $\left(0.04 \mathrm{ng} \mathrm{g}^{-1} \mathrm{ww}\right)$ was applied. Prior to further analyses, a series of exploratory steps, following Zuur et al., ${ }^{47}$ were completed to understand the structure of POP concentration data (heteroscedasticity, normality, and outliers) and to inform the selection of further statistical tests and models.

To address the first hypothesis, we analyzed covariation in POP and transfer pathway data directly using generalized linear models (GLMs) ${ }^{48}$ with contaminant body burden data and data regarding the proportion of secondary production associated with the two types of basal resources (allochthonous and autochthonous). In addition to this, these data were also used to calculate metrics describing the accumulation, magnification, and transfer of POPs between organisms sampled from the T1 food web. Sediment bioaccumulation factors (BSAFs) for each taxon sampled were calculated using tissue concentration data in conjunction with the concentrations measured in sediment samples, following eq 1

$$
\mathrm{BSAF}=\frac{C_{\mathrm{B}}}{C_{\mathrm{STO}}}
$$

where $C_{\mathrm{B}}$ is the concentration of POP groups (PBDEs, PCBs, and OCs) measured in the tissues of the target organism (ng $\mathrm{g}^{-1} \mathrm{ww}$ ) and $\mathrm{C}_{\mathrm{STO}}$ is the concentration measured in organic matter and sediments ( $\left.\mathrm{ng} \mathrm{g}^{-1} \mathrm{ww}\right)$. Biomagnification factors (BMFs) were also calculated for taxa across the food web to assess the organism-specific levels of biomagnification, following eq 2

$$
\mathrm{BSAF}=\frac{C_{\mathrm{B}}}{\sum P_{i} C_{\mathrm{D} i}}
$$

where $C_{B}$ is the concentration of xenobiotic pollutants measured in the tissues of the target organism ( $\left.\mathrm{ng} \mathrm{g}^{-1} \mathrm{ww}\right)$, $P_{i}$ is the proportion of the prey organism or basal resource (sediments, detritus, plant material, or microbial biofilm) observed in the diet of the target organism $i(0-1)$, and $C_{\mathrm{D} i}$ is the concentration of persistent pollutants measured in the tissues of the prey organism $i\left(\mathrm{ng} \mathrm{g}^{-1} \mathrm{ww}\right)$.

For the second hypothesis, we used trait data for the macroinvertebrates sampled at the $\mathrm{T} 1$ food web, collated from a European fuzzy-coded trait database, ${ }^{49}$ to investigate intertaxon variation within communities ${ }^{50,51}$ and understand the consequences of such a structure for the transfer of pollutants. These trait data were supplemented by nonfuzzy, categorized feeding guild data for macroinvertebrate taxa of South Wales (Durance I \& Ormerod S J, unpublished data). Traits included those expected to be directly related to the accumulation of pollutants (e.g., feeding behavior, trophic levels, and habitat affinity) and those that may indirectly alter accumulation, for example, factors that determine the distribution of organisms in river systems and the pollution tolerance of taxa. In the following analyses, disaggregated trait data were utilized to assess the relationships between biological traits and bioaccumulation and biomagnification of POPs. Prior to trait-based modeling, trait affinity data were standardized across grouping features (overarching trait groups, e.g., feeding preference) to allow for improved comparisons between different traits and organisms. The exact methods used in the preparation and standardization of fuzzy-coded trait data are described in more detail by Gutiérrez-Cánovas et al. ${ }^{52}$ Traits were selected initially based on their correlation with the BSAFs for each chemical group (PBDEs, PCBs, and OCs; Appendix S3) across the sampled taxa in the T1 river food web. We use BSAF values in models to minimize the effect of concentration dependence which influences bioaccumulation of POPs and restricts the applicability of these 
Table 2. BSAFs and BMFs for PCBs, PBDEs, and OCs Across Organisms in the T1 River Food Web

\begin{tabular}{|c|c|c|c|c|c|c|c|c|c|}
\hline \multirow[b]{2}{*}{ sample } & \multicolumn{2}{|c|}{$\begin{array}{l}\text { trophic level } \\
\text { (averaged) }\end{array}$} & \multirow[t]{2}{*}{ carbon ratio (auto/allo) } & \multicolumn{3}{|c|}{ BSAF } & \multicolumn{3}{|c|}{ BMF } \\
\hline & chain & prey & & $\sum$ PBDEs & $\sum \mathrm{PCBs}$ & $\sum \mathrm{OCs}$ & $\sum$ PBDEs & $\sum \mathrm{PCBs}$ & $\sum \mathrm{OCS}$ \\
\hline Asellus aquaticus & 2.00 & 2.00 & 0.49 & 2.04 & & 0.21 & 0.49 & & 0.37 \\
\hline Leuctra spp. & 2.00 & 2.00 & 0.09 & 4.15 & 4.48 & 1.02 & 0.99 & 4.55 & 2.73 \\
\hline Rhithrogena semicolorata & 2.00 & 2.00 & 4.98 & 7.64 & & 0.89 & 1.03 & & 7.99 \\
\hline Caenis spp. & 2.00 & 2.00 & 0.50 & 4.59 & & 0.92 & 1.09 & & 1.58 \\
\hline Naididae & 2.00 & 2.00 & 0.49 & 5.06 & & 0.38 & 1.20 & & 1.63 \\
\hline Ecdyonurus spp. & 2.00 & 2.00 & 5.01 & 4.48 & 0.62 & 0.34 & 0.61 & 0.64 & 0.37 \\
\hline Baetis spp. & 2.00 & 2.00 & 2.00 & 13.68 & 0.20 & 0.65 & 3.25 & 0.21 & 0.68 \\
\hline Radix spp. & 2.00 & 2.00 & 0.49 & 5.07 & 1.61 & 0.84 & 1.21 & 1.64 & 0.60 \\
\hline Heptagenia spp. & 2.00 & 2.00 & 2.01 & 6.21 & 1.40 & 0.32 & 1.48 & 1.42 & 1.15 \\
\hline Eiseniella tetraedra & 2.00 & 2.00 & 0.11 & 7.51 & 4.35 & 0.81 & 1.79 & 4.41 & 1.67 \\
\hline Lepidostoma hirtum & 2.00 & 2.00 & 0.49 & 5.12 & & 3.22 & 1.22 & & 1.26 \\
\hline Simuliidae & 5.20 & 3.49 & 0.49 & 4.19 & 0.24 & 0.05 & 1.00 & 0.33 & 1.28 \\
\hline Serratella ignita & 5.24 & 3.26 & 4.99 & 6.69 & 0.43 & 0.94 & 0.90 & 0.44 & 2.49 \\
\hline Sericostoma personatum & 7.60 & 3.29 & 0.51 & 36.95 & 0.47 & 12.08 & 7.13 & 0.72 & 0.51 \\
\hline Gammarus pulex & 8.06 & 3.44 & 0.02 & 6.02 & 0.13 & 0.71 & 0.99 & 0.09 & 1.01 \\
\hline Hydropsyche spp. & 8.69 & 3.31 & 0.37 & 28.60 & 0.51 & 7.42 & 5.64 & 0.43 & 3.77 \\
\hline Polycelis spp. & 8.77 & 3.61 & 0.39 & 31.19 & 0.60 & 16.98 & 7.55 & 0.50 & 26.63 \\
\hline Platambus maculatus & 9.44 & 3.58 & 0.17 & 23.24 & 4.12 & 1.54 & 23.24 & 5.42 & 6.65 \\
\hline Rhyacophila dorsalis & 9.98 & 3.29 & 0.62 & 6.28 & & 2.93 & 0.85 & & 6.41 \\
\hline Polycentropus spp. & 10.14 & 3.29 & 0.57 & 7.13 & & 3.61 & 0.94 & & 1.97 \\
\hline E. octoculata & 10.80 & 3.55 & 0.52 & 13.84 & 2.99 & 0.78 & 96.91 & 20.90 & 51.96 \\
\hline C. gobio & 11.09 & 4.23 & 0.56 & 123.03 & 28.79 & 6.08 & 9.62 & 22.73 & 2.89 \\
\hline
\end{tabular}

Table 3. Results of Predictive Trait-Based Models Relating Biological Traits to POP BSAFs in the T1 Food Web ${ }^{a, b}$

\begin{tabular}{|c|c|c|c|c|c|c|}
\hline pollutant & $\mathrm{AICc}$ & $R^{2}$ & grouping feature (trait) & effect $( \pm S E)$ & $t$ & $p$ \\
\hline \multirow{5}{*}{ ¿PBDEs } & 38.40 & 0.69 & trophic level (chain averaged) & $0.11(0.03)$ & 3.46 & 0.003 \\
\hline & & & feeding behavior (functional feeding guild) & $1.93(0.71)$ & 2.78 & 0.081 \\
\hline & & & longitudinal distribution (estuary) & $-3.27(1.23)$ & -2.65 & 0.017 \\
\hline & & & substrate (microphytes) & $-2.36(3.01)$ & -0.79 & 0.445 \\
\hline & & & reproduction (isolated cemented eggs) & $0.64(0.25)$ & 2.56 & 0.021 \\
\hline \multirow[t]{5}{*}{$\Sigma \mathrm{PCBs}$} & 76.81 & 0.47 & trophic level (chain averaged) & $0.17(0.19)$ & 0.87 & 0.235 \\
\hline & & & feeding behavior (functional feeding guild) & $1.71(1.36)$ & 1.25 & 0.027 \\
\hline & & & longitudinal distribution (estuary) & $-5.30(4.27)$ & -1.81 & 0.201 \\
\hline & & & transversal distribution (banks and side pools) & $2.57(2.73)$ & 0.95 & 0.113 \\
\hline & & & respiration (gills) & $-1.91(1.23)$ & -1.55 & 0.042 \\
\hline \multirow[t]{6}{*}{$\Sigma \mathrm{OCs}$} & 54.10 & 0.84 & trophic level (chain averaged) & $0.14(0.06)$ & 2.77 & 0.019 \\
\hline & & & feeding behavior (functional feeding guild) & $1.77(0.55)$ & 3.23 & 0.009 \\
\hline & & & dispersal mode (active aquatic) & $3.21(0.82)$ & 3.91 & 0.003 \\
\hline & & & reproduction (clutch cemented eggs) & $0.40(0.22)$ & 1.83 & 0.098 \\
\hline & & & substrate (twigs and detritus) & $-0.55(1.51)$ & -0.55 & 0.593 \\
\hline & & & saprobity (oligosaprobic) & $4.57(0.83)$ & 5.49 & $<0.001$ \\
\hline
\end{tabular}

${ }^{a}$ Relationships are presented as trait affinities within grouping features (see Methods and Materials). Data were derived from both fuzzy-coded trait databases and food web data. ${ }^{b} \mathrm{AICc}=$ corrected Akaike information criterion; effect $=$ effect size from GLM; SE $=$ standard error; $t=t$-statistic from a Wald test.

models to other food webs where environmental concentrations may differ from those observed at the $\mathrm{T} 1$ food web. This allows for predictions across multiple sites, used to test the third hypothesis. Traits with an average coefficient of $R \geq$ I 0.40 l were selected for further analysis. For this subset of traits, the relationships between trait affinity and the BSAF values for PBDEs, PCBs, and OCs were assessed using GLMs. Global models were constructed for each chemical using the corrected Akaike information criterion (AICc) and the dredge function in "MuMin". 53 GLMs were then validated following procedures detailed by Zuur et al. ${ }^{54}$ and Thomas et al. ${ }^{55}$ Residual normality was assessed using QQ plots, homogeneity of variance was determined by plotting residuals against fitted values, and influential observations were investigated using Cook's leverage distances.

The third hypothesis was tested using the BSAF GLMs (detailed above), a steady-state equation for estimating chemical bioaccumulation (AQUAWEB 1.2; Arnot and Gobas $^{38}$ ), and a wider dataset of BSAFs calculated for invertebrate taxa from eight other river food webs sampled across South Wales, UK (Windsor; ${ }^{56}$ Figure 1). AQUAWEB models the bioaccumulation of nonionic hydrophobic pollutants in organisms from concentrations in sediments and water by calculating the uptake and dietary transfer of chemicals. The model uses a series of toxicokinetic and toxicodynamic equations to predict the steady-state concen- 
trations of compounds in compartments of the environment. ${ }^{38}$ Through comparisons between the predictions from these two models and measured BSAFs, we assess the relative accuracy of both trophic- and trait-based models. Here, we use the mean absolute error (MAE; Willmott and Matsuura ${ }^{57}$ ) calculated for relationships between the observed and predicted BSAFs to assess the performance and accuracy of models.

\section{RESULTS}

4.1. Concentrations of PCBs, PBDEs, and OCs in the T1 Food Web. POP concentrations varied widely in organisms at $\mathrm{T} 1$ (Table 1), and over $55 \%$ of compounds analyzed were detected in $<10 \%$ of samples. This was particularly true for some of the scarcer congeners, and, for example, PCBs 31, 126, and 157 were only observed in sediments and microbial biofilms. Conversely, PBDE congeners 28, 49, 99, 100, 153, and 154, PCB 52, and p, $p^{\prime}$-DDT were only observed in tissue samples from invertebrates and fish. Rather than treatment at the congener level, therefore, concentration data were aggregated for different chemical groups (PCBs, PBDEs, and OCs) in further assessments of bioaccumulation and trophic magnification.

Total concentrations of PBDEs (coefficient of variation $[\mathrm{CV}]=0.61)$, PCBs $(\mathrm{CV}=0.51)$, and OCs $(\mathrm{CV}=0.64)$ remained highly variable across the $\mathrm{T} 1$ food web even after aggregation (Table 1). This, in part, reflected the magnification of POPs across trophic levels (Table 2), with predators such as Cottus gobio, Erpobdella octoculata, and Polycelis spp. having the highest total concentrations of PBDEs, PCBs, and OCs. The trophic level did not explain all the variations, however (Table 3 ), and even some organisms feeding on the same resources and occupying the same trophic level had significantly differing pollutant concentrations at the same sample site (Table 1).

4.2. Transfer Pathways of POPs through the T1 Food Web. Trophic transfer pathways at $\mathrm{T} 1$ appeared to differ among PBDEs, PCBs, and OCs (Table 2). Chlorinated compounds, particularly PCBs, were associated with the flux of allochthonous carbon from benthic detritus and organic matter (plant fragments) in samples from sediments, with higher concentrations observed in taxa making use of a greater proportion of these resources (Table 2 and Figure 2). Taxa consuming a greater mass of allochthonous resources, as well as those consuming secondary production derived from allochthonous resources, appeared to have higher PCB concentrations $\left(R^{2}=0.22, F_{1,20}=5.68, p=0.027\right)$. In comparison, higher concentrations of PBDEs were associated with the flux of autochthonous carbon, increasing in taxa consuming primary and secondary production derived from microbial biofilms $\left(R^{2}=0.48, F_{1,20}=10.79, p<0.001\right)$. Despite these significant relationships, the low $R^{2}$ values in these for models indicate unexplained variation in POP concentrations, and there was no relationship with either autochthonous or allochthonous carbon consumption and the concentrations or flux of OCs $\left(R^{2}=0.02, F_{1,20}=0.33, p=0.574\right)$. The majority of residual variation instead reflected the biological traits of different invertebrates, and this is considered below (Table 3).

4.3. Influence of Biological Traits on Bioaccumulation. Concentrations of POPs across the invertebrate food web were variable and related to biological traits, for example, habitat affinity, substrate use, body size, and voltinism (Table 3). Although there was some variation across chemical groups, biological traits explained a significant amount of the variation in PBDEs, PCBs, and OCs across the food web (Table 3).
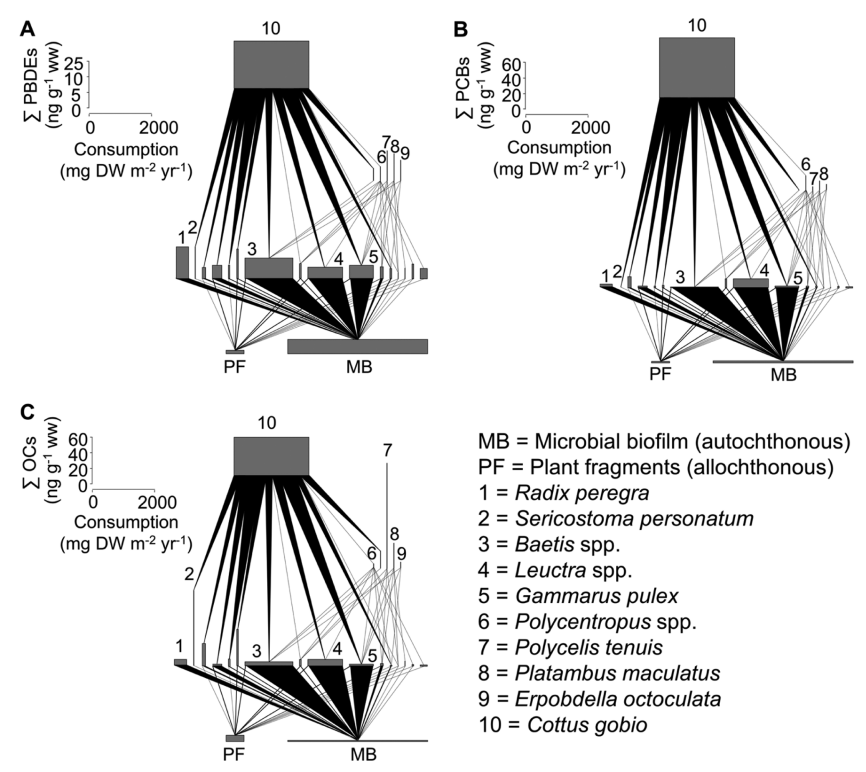

$\mathrm{MB}=$ Microbial biofilm (autochthonous) $\mathrm{PF}=$ Plant fragments (allochthonous) $1=$ Radix peregra

2 = Sericostoma personatum

$3=$ Baetis spp.

$4=$ Leuctra spp.

$5=$ Gammarus pulex

$6=$ Polycentropus spp

$7=$ Polycelis tenuis

8 = Platambus maculatus

$9=$ Erpobdella octoculata

$10=$ Cottus gobio

Figure 2. Quantitative food webs representing the flux of organic matter through the T1 river food web. Data used to construct food webs were collected from monthly samples over an annual cycle (2016-2017). Food webs were summarized into four approximate trophic levels: the lowest bars are basal resources, the middle bars are primary and secondary macroinvertebrate consumers, respectively, and the top bar is a predatory fish taxon (C.gobio). The relative height and width of bars correspond to the concentration of POP groups (PBDEs, PCBs, and OCs) and the total consumption (total biomass flux from resources to consumers) for each taxon, respectively (see inset scales). The width of bars for basal resources relates to the total consumption of the resource by macroinvertebrate consumers (total flux from each resource to consumers). Black triangles linking the trophic levels are the contributions of resource fluxes to production in each consumer, aggregating to total inflow. The concentrations of each group of POPs measured in the tissues of organisms are reported on a wet weight basis $\left(\mathrm{ng} \mathrm{g}^{-1} \mathrm{ww}\right)$.

Models constructed from biological traits in the T1 food web were able to predict BSAFs for PBDEs and OCs $\left(R^{2}=0.92\right.$, $F_{1,61}=712.60, p<0.001$; Figure $3 \mathrm{~A}$ ) with a relatively low error $(\mathrm{MAE}=0.14)$. For PCBs, the prediction of BSAF values was hindered by the low detection frequency (Table 1), which resulted in a relatively poor $R^{2}$ in the model. As such, BSAFs for PCBs were not predicted for validation sites.

4.4. Multimodel Comparisons. In trait-based models used to predict BSAFs for invertebrates more widely across South Wales, the PCB model was the weakest $\left(R^{2}=0.47\right.$; Figure $3 \mathrm{~B})$. In contrast, for both OCs and PBDEs, trait-based models outperformed the AQUAWEB model for predicting BSAFs across the catchments (Figure 3), with trait-based models having stronger linear relationships between the observed and predicted values $\left(R^{2}=0.22, F_{1,82}=28.55, p<\right.$ $0.001)$, as well as lower MAE for PBDEs and OCs, in comparison to AQAUWEB $\left(R^{2}=0.03, F_{1,82}=2.51, p=0.117\right)$. The inclusion of biological traits describing habitat affinities, physiological characteristics, and trophic factors thus improved the accuracy and precision of predictions, although significant unexplained variation remained $\left(R^{2}=0.22\right)$. In general, predictions from the AQUAWEB model for PBDEs and PCBs were hindered by the infrequent detection of POPs in sediments (coarse sand and the gravel substrate), which often had concentrations below the mean limits of detection $(\sim 0.04$ $\left.\mathrm{ng} \mathrm{g}^{-1} \mathrm{ww}\right)$. As trait-based models were not reliant on 

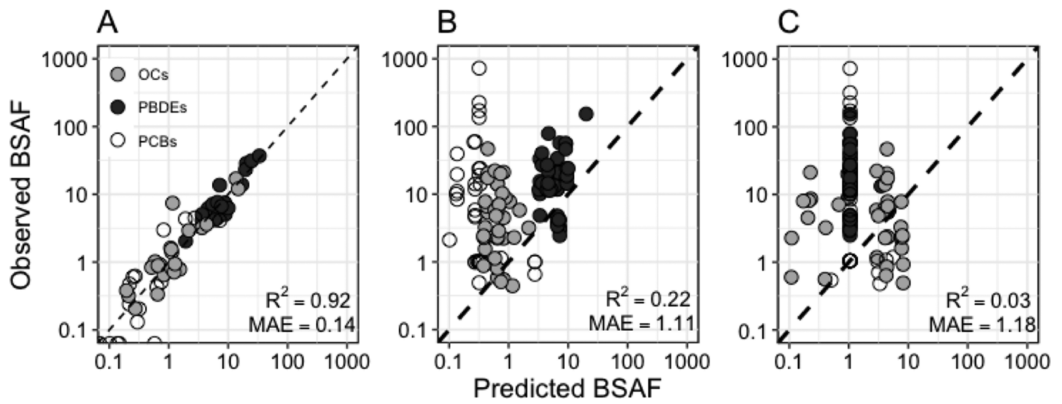

Figure 3. Predicted vs observed POP BSAFs for trait-based and steady-state model data across river food webs in South Wales (UK). (A) Data from the $\mathrm{T} 1$ food web. (B) Trait-based model predictions for validation data. (C) AQUAWEB 2.0 predictions for validation data. Validation data from Windsor (2019). Individual data points represent BSAFs calculated for individual organisms. Solid black lines indicate a 1:1 relationship between the observed and predicted BSAF values. PCBs were excluded from statistical analyses because of the low detection frequency in chemical analyses, and thus the restricted proportion of explained variance in models which reduced the predictive ability of the trait-based model (presented here as hollow points).

environmental concentration data, they were less affected by this problem.

\section{DISCUSSION}

The flux of POPs through the T1 river food web occurred through pathways linked to primary and secondary production arising from both allochthonous and autochthonous resources. These trophic transfers did not explain all the variations in the POP concentrations measured in organisms, and POP bioaccumulation was related to the physiological, ecological, and behavioral biological traits of organisms. Trait-based models constructed from 20 invertebrate taxa captured significant variation in the BSAFs for POP compounds across a wider suite of river food webs across South Wales. Despite performing better than steady-state equations, however, traitbased models were only able to estimate BSAFs to within 1 order of magnitude. Both these prediction methods were hindered by the low detection frequencies of POPs across environmental matrices (sediments and biofilms), as well as the significant variation in bioaccumulation not related to the combination of trophic interactions, biological traits, or environmental concentrations of POPs. In total, these findings not only show how physiological, phenological, and behavioral traits, as well as trophic characteristics of organisms (e.g., feeding habits), affect the flux and accumulation of POPs but also highlight the variable nature of pollutant transfers across aquatic food webs.

There are several caveats over field-based assessments of pollutant transfers through food webs that should be considered when interpreting our findings. First, although trait diversity was relatively high within the $\mathrm{T} 1$ food web, only a single food web was analyzed in depth. Focusing on a single food web increased the potential influence of site-specific characteristics but limited the potentially confounding variation associated with the structure of food webs and environmental conditions while capturing greater taxonomic and functional diversity than the previous assessments. This, in turn, allowed for the construction of trait-based models and enabled predictions across sites. Second, there remain challenges associated with the use of fuzzy-coded trait data: ${ }^{21}$ despite representing noisy data (e.g., size, feeding behavior, and substrate preferences), the multivariate nature of fuzzy coding makes the statistical assessment of relationships between groups of traits (e.g., feeding behavior), trait affinities, and other variables difficult. Our study assessed relationships between trait affinities and BSAF values, yet a more parsimonious approach would be to summarize the multivariate trait characteristics of individual taxa prior to modeling. Nevertheless, although trait-space methods exist for summarizing and understanding the diversity of traits across taxa or communities (e.g., Gutiérrez-Cánovas et al. ${ }^{52}$ ), there are few suitable methods for consolidating fuzzy-coded trait data regarding individual taxa for predictive modeling purposes. Notwithstanding these caveats, our findings provide novel information about transfer pathways and the influence of biological traits on pollutant dynamics in natural systems.

Contaminant data coupled with information on the flux of energy and material across trophic interactions indicated multiple transfer pathways of PBDEs, PCBs, and OCs through the T1 food web. Although widely detected, groups of POPs (PBDEs, PCBs, and OCs) appeared to be differentially distributed across food web compartments, with initial partitioning occurring in the basal resources and a subsequent proliferation through the network alongside the transfer of different resources. Such partitioning and differential distribution of POPs across the basal resources and across the wider food web may result from several factors. First, the chemical properties of pollutants (e.g., partitioning coefficients) might alter the accumulation of POPs and generate differential accumulation across food webs. Characteristics such as polarity, hydrophobicity, and lipophilicity $\left(\log K_{\mathrm{OW}}\right)$, as well as half-life (degradability), all influence the potential distribution of pollutants in the aquatic environment. For example, it has been previously shown that OCs have a high affinity for fine sediments ${ }^{58}$ and plant detritus, ${ }^{59}$ while PBDEs have been observed in high concentrations in microbial biofilms. ${ }^{60}$ Thus, it may be that the affinity of different pollutant groups varies across these resources, and the interaction between the chemical properties of the pollutants and basal resources (e.g., organic matter content, polarity, and hydrophobicity) could explain variable distributions across compartments. A second potential explanation is that pollutants may be partitioned as a result of their sources across the environment. For example, OCs and PCBs are often more prevalent in sediments and benthic organic matter as a result of their remobilization across catchments (e.g., de Perre et al. $^{61}$ ). In comparison, PBDEs may be present in microbial biofilms as a result of their more contemporary emissions, greater aqueous concentrations, and thus greater potential for storage in surficial biofilms (e.g., Bartons et al. ${ }^{62}$ ). Certainly, 
the presence of highly brominated congeners across the food web indicates the potential for recent or active emissions, as these congeners are liable to degrade into less brominated congeners in the environment. ${ }^{63}$ Despite all plausible explanations, the exact mechanism responsible for the observed partitioning of different chemical groups across the food web remains uncertain. Further research, across multiple food webs, is also required to understand whether these patterns are present across multiple systems or whether this is an artifact of environmental conditions present in our study.

Concentrations and levels of bioaccumulation of all the POPs in the $\mathrm{T} 1$ food web were related to variation in the biological traits of organisms. Some traits appeared to consistently influence the concentrations of POP compounds, for example, affinity of organisms with different habitats in river systems (e.g., side pools, slow flowing regions of the channel, and lowland systems), feeding behavior (e.g., predators, filterers, and grazers) and organism trophic levels. Such patterns, in particular associations with the feeding habitat, have been observed widely across aquatic food webs. $^{19,22,64-66}$ The other statistical relationships between ecological and behavioral traits further point toward the potential for the differential distribution of persistent compounds across the longitudinal and transversal profile of river systems. As a specific example, in the T1 food web, organisms associated with side pools, twigs, detritus, and lowland stream systems exhibited higher OC, PCB, and PBDE body burdens. Similar observations in tropical food webs for OCs reveal that slow-flowing stream regions support greater volumes of fine sediment and detritus, facilitating an enhanced bioavailability and bioaccumulation of chemicals. ${ }^{67}$ However, in general relationships such as this remain poorly understood. Other trait-pollutant relationships were specific to individual compounds. For example, OC bioaccumulation was greater in smaller organisms, potentially as a result of the biotransformation of compounds within larger invertebrates at higher trophic levels in the food web, as is shown for other organic pollutants. $^{68}$ The absence of this allometric relationship for PCBs and PBDEs may result from the fact that these chemicals are not rapidly transformed, for example, the absence of $\mathrm{PCB}$ congener biotransformation in the tissues of mysids. ${ }^{69}$ Here again, there is uncertainty about the basis for these relationships, especially as many processes related to the transformation of persistent chemicals are difficult to assess in natural systems without further information on chiral congeners. 69

The enhanced accuracy of predictions from trait-based models, in comparison to steady-state equations, complements previous research that suggests that the biological and ecological characteristics of food webs strongly influence the levels of accumulation and magnification. ${ }^{15}$ Furthermore, this supports previous studies which have also shown the relatively limited effectiveness of steady-state models (traditional firstorder, single compartment models) for predicting field-based BSAFs for organisms within river food webs because of the fact that these models do not encapsulate dynamic processes. ${ }^{70}$ Trait-models, however, were only able to predict BSAFs with approximately an order of magnitude accuracy, and large variation in BSAFs were observed across the wider suite of river food webs. This points toward exogenous drivers of variation in the bioaccumulation of POPs across these food webs. The unexplained variation likely results from differences in the bioavailability of POPs across sites or significant differences in the structure of the food webs. We thus suggest that the trait-based models presented here explained the existing variation in bioaccumulation associated with biological traits, yet environmental variation and the remaining broadscale biological variation, relating to the food web structure, perturbed accurate predictions.

Although only marginally better than existing methods in this study, the development of trait-based analyses is important, with several potential benefits. First, modeling with invertebrate traits, which are conserved across continental scales, ${ }^{71}$ provides a potential technique for large scale monitoring of the ecological risk from contaminants. Based on the assumption that taxa with similar biological traits respond similarly to pollutant exposure, the problems associated with highly variable regional taxonomy, and thus challenges in estimating risk for individual species, could be avoided. Second, such methods present an opportunity for early-warning tools to indicate the potential risk of bioaccumulation or ecological effects for organisms with specific combinations of biological traits. The development of such tools may contribute to important next steps in improving assessments of risk relating to chemicals in advance of their introduction to the environment (see Godfray et al. ${ }^{72}$ ). More research is required to understand just how widely applicable trait-based methods are for predicting accumulation and ecological risk in different systems.

In summary, findings from this study demonstrate the importance of transfer pathways and biological traits in influencing the bioaccumulation and trophic magnification of pollutants across a riverine food web. Specific groups of chemicals were shown to accumulate differentially, in response to a variety of resources and transfer pathways within the food web. Magnification occurred for all the compounds, yet biological traits influenced the relationship between the trophic level and observed bioaccumulation-indicating that organisms occupying the same trophic level may be differentially exposed to POPs. Trait-based models relatively predicted the bioaccumulation of POPs across multiple sample sites in South Wales relatively accurately. The trait-based model required less prior knowledge compared to other bioaccumulation models, such as AQUAWEB, and was based on publicly available trait data for freshwater invertebrates. This study demonstrates the importance of biological traits for the trophic transfer of pollutants and indicates the potential power of trait-based analyses for the prediction of food web scale ecotoxicological processes.

\section{ASSOCIATED CONTENT}

\section{S Supporting Information}

The Supporting Information is available free of charge on the ACS Publications website at DOI: 10.1021/acs.est.9b05891.

Equations for trophic basis of production, taxa list for the T1 food web, trait data for sampled taxa, limits of detection for gas chromatography-mass spectrometry, and relationships between traits and contaminant bioaccumulation (PDF)

Raw persistent organic compound concentration data for samples (TXT)

\section{AUTHOR INFORMATION}

\section{Corresponding Author}

*E-mail: fredric.windsor@newcastle.ac.uk. 


\section{ORCID $\odot$}

Fredric M. Windsor: 0000-0001-5030-3470

Stephen J. Ormerod: 0000-0002-8174-302X

\section{Present Address}

"School of Natural and Environmental Sciences, Newcastle University, Newcastle upon Tyne, Tyne and Wear, NE1 7RU, UK.

\section{Notes}

The authors declare no competing financial interest.

\section{ACKNOWLEDGMENTS}

This work was supported by a studentship through the GW4+ Doctoral Training Partnership from the Natural Environment Research Council [NE/L002434/] (F.M.W.). The authors thank the Environment Agency and Natural Resources Wales for providing secondary data. F.M.W. would like to thank Heather Carter and Alex Hunter at $\mathrm{CEH}$ for assistance with chemical analyses of POPs. Finally, thanks to the many research assistants for help with data collection and sample processing.

\section{REFERENCES}

(1) Malaj, E.; von der Ohe, P. C.; Grote, M.; Kühne, R.; Mondy, C. P.; Usseglio-Polatera, P.; Brack, W.; Schäfer, R. B. Organic Chemicals Jeopardize the Health of Freshwater Ecosystems on the Continental Scale. Proc. Natl. Acad. Sci. U.S.A. 2014, 111, 9549-9554.

(2) Windsor, F. M.; Ormerod, S. J.; Tyler, C. R. Endocrine Disruption in Aquatic Systems: Up-Scaling Research to Address Ecological Consequences. Biol. Rev. 2018, 93, 626-641.

(3) López-Doval, J. C.; Ricart, M.; Guasch, H.; Romaní, A. M.; Sabater, S.; Muñoz, I. Does Grazing Pressure Modify Diuron Toxicity in a Biofilm Community? Arch. Environ. Contam. Toxicol. 2010, 58, 955-962.

(4) Soin, T.; Smagghe, G. Endocrine Disruption in Aquatic Insects: A Review. Ecotoxicology 2007, 16, 83-93.

(5) Kloas, W.; Urbatzka, R.; Opitz, R.; Würtz, S.; Behrends, T.; Hermelink, B.; Hofmann, F.; Jagnytsch, O.; Kroupova, H.; Lorenz, C.; et al. Endocrine Disruption in Aquatic Vertebrates. Ann. N.Y. Acad. Sci. 2009, 1163, 187-200.

(6) Morrissey, C. A.; Stanton, D. W. G.; Tyler, C. R.; Pereira, M. G.; Newton, J.; Durance, I.; Ormerod, S. J. Developmental Impairment in Eurasian Dipper Nestlings Exposed to Urban Stream Pollutants. Environ. Toxicol. Chem. 2014, 33, 1315-1323.

(7) Chagnon, M.; Kreutzweiser, D.; Mitchell, E. A. D.; Morrissey, C. A.; Noome, D. A.; Van der Sluijs, J. P. Risks of Large-Scale Use of Systemic Insecticides to Ecosystem Functioning and Services. Environ. Sci. Pollut. Res. 2015, 22, 119-134.

(8) McKnight, U. S.; Rasmussen, J. J.; Kronvang, B.; Binning, P. J.; Bjerg, P. L. Sources, Occurrence and Predicted Aquatic Impact of Legacy and Contemporary Pesticides in Streams. Environ. Pollut. 2015, 200, 64-76.

(9) Rasmussen, J. J.; Wiberg-Larsen, P.; Baattrup-Pedersen, A.; Cedergreen, N.; McKnight, U. S.; Kreuger, J.; Jacobsen, D.; Kristensen, E. A.; Friberg, N. The Legacy of Pesticide Pollution: An Overlooked Factor in Current Risk Assessments of Freshwater Systems. Water Res. 2015, 84, 25-32.

(10) Streets, S. S.; Henderson, S. A.; Stoner, A. D.; Carlson, D. L.; Simcik, M. F.; Swackhamer, D. L. Partitioning and Bioaccumulation of PBDEs and PCBs in Lake Michigan. Environ. Sci. Technol. 2006, 40, $7263-7269$.

(11) Wu, J.-P.; Luo, X.-J.; Zhang, Y.; Yu, M.; Chen, S.-J.; Mai, B.-X.; Yang, Z.-Y. Biomagnification of Polybrominated Diphenyl Ethers (PBDEs) and Polychlorinated Biphenyls in a Highly Contaminated Freshwater Food Web from South China. Environ. Pollut. 2009, 157, 904-909.
(12) Kelly, B. C.; Ikonomou, M. G.; Blair, J. D.; Morin, A. E.; Gobas, F. A. P. C. Food Web-Specific Biomagnification of Persistent Organic Pollutants. Science 2007, 317, 236-239.

(13) Walters, D. M.; Jardine, T. D.; Cade, B. S.; Kidd, K. A.; Muir, D. C. G.; Leipzig-Scott, P. Trophic Magnification of Organic Chemicals: A Global Synthesis. Environ. Sci. Technol. 2016, 50, 4650-4658.

(14) Walters, D. M.; Mills, M. A.; Cade, B. S.; Burkard, L. P. Trophic Magnification of PCBs and Its Relationship to the Octanol-water Partition Coefficient. Environ. Sci. Technol. 2011, 45, 3917-3924.

(15) Walters, D. M.; Fritz, K. M.; Johnson, B. R.; Lazorchak, J. M.; McCormick, F. H. Influence of Trophic Position and Spatial Location on Polychlorinated Biphenyl (PCB) Bioaccumulation in a Stream Food Web. Environ. Sci. Technol. 2008, 42, 2316-2322.

(16) Meador, J. P.; Adams, W. J.; Escher, B. I.; McCarty, L. S.; McElroy, A. E.; Sappington, K. G. The Tissue Residue Approach for Toxicity Assessment: Findings and Critical Reviews from a Society of Environmental Toxicology and Chemistry Pellston Workshop. Integr. Environ. Assess. Manage. 2011, 7, 2-6.

(17) Escher, B. I.; Ashauer, R.; Dyer, S.; Hermens, J. L.; Lee, J.-H.; Leslie, H. A.; Mayer, P.; Meador, J. P.; Warne, M. S. Crucial Role of Mechanisms and Modes of Toxic Action for Understanding Tissue Residue Toxicity and Internal Effect Concentrations of Organic Chemicals. Integr. Environ. Assess. Manage. 2011, 7, 28-49.

(18) Kelly, B. C.; Ikonomou, M. G.; Blair, J. D.; Gobas, F. A. P. C. Bioaccumulation behaviour of polybrominated diphenyl ethers (PBDEs) in a Canadian Arctic marine food web. Sci. Total Environ. 2008, 401, 60-72.

(19) Fisk, A. T.; Hobson, K. A.; Norstrom, R. J. Influence of Chemical and Biological Factors on Trophic Transfer of Persistent Organic Pollutants in the Northwater Polynya Marine Food Web. Environ. Sci. Technol. 2001, 35, 732-738.

(20) Brett, M. T.; Bunn, S. E.; Chandra, S.; Galloway, A. W. E.; Guo, F.; Kainz, M. J.; Kankaala, P.; Lau, D. C. P.; Moulton, T. P.; Power, M. E.; et al. How Important Are Terrestrial Organic Carbon Inputs for Secondary Production in Freshwater Ecosystems? Freshwater Biol. 2017, 62, 833-853.

(21) Menezes, S.; Baird, D. J.; Soares, A. M. V. M. Beyond Taxonomy: A Review of Macroinvertebrate Trait-Based Community Descriptors as Tools for Freshwater Biomonitoring. J. Appl. Ecol. 2010, 47, 711-719.

(22) Sidney, L. A.; Diepens, N. J.; Guo, X.; Koelmans, A. A. TraitBased Modelling of Bioaccumulation by Freshwater Benthic Invertebrates. Aquat. Toxicol. 2016, 176, 88-96.

(23) Rubach, M. N.; Ashauer, R.; Buchwalter, D. B.; De Lange, H.; Hamer, M.; Preuss, T. G.; Töpke, K.; Maund, S. J. Framework for Traits-Based Assessment in Ecotoxicology. Integr. Environ. Assess. Manage. 2011, 7, 172-186.

(24) Diepens, N. J.; Van den Heuvel-Greve, M. J.; Koelmans, A. A. Modeling of Bioaccumulation in Marine Benthic Invertebrates Using a Multispecies Experimental Approach. Environ. Sci. Technol. 2015, 49, 13575-13585.

(25) Gaskell, P. N.; Brooks, A. C.; Maltby, L. Variation in the Bioaccumulation of a Sediment-Sorbed Hydrophobic Compound by Benthic Macroinvertebrates: Patterns and Mechanisms. Environ. Sci. Technol. 2007, 41, 1783-1789.

(26) Schmera, D.; Podani, J.; Heino, J.; Erôs, T.; Poff, N. L. A Proposed Unified Terminology of Species Traits in Stream Ecology. Freshw. Sci. 2015, 34, 823-830.

(27) Williams, A. T.; Simmons, S. L. Sources of Riverine Litter: The River Taff, South Wales, UK. Water, Air, Soil Pollut. 1999, 112, 197216.

(28) Vaughan, I. P.; Ormerod, S. J. Large-Scale, Long-Term Trends in British River Macroinvertebrates. Glob. Chang. Biol. 2012, 18, 2184-2194.

(29) Windsor, F. M.; Pereira, M. G.; Tyler, C. R.; Ormerod, S. J. Persistent Contaminants as Potential Constraints on the Recovery of Urban River Food Webs from Gross Pollution. Water Res. 2019, 163, 114858 . 
(30) Tocher, D. R. Metabolism and Functions of Lipids and Fatty Acids in Teleost Fish. Rev. Fish. Sci. 2003, 11, 107-184.

(31) Monosson, E.; Ashley, J. T. F.; McElroy, A. E.; Woltering, D.; Elskus, A. A. PCB Congener Distributions in Muscle, Liver and Gonad of Fundulus Heteroclitus from the Lower Hudson River Estuary and Newark Bay. Chemosphere 2003, 52, 777-787.

(32) Borghesi, N.; Corsolini, S.; Focardi, S. Levels of Polybrominated Diphenyl Ethers (PBDEs) and Organochlorine Pollutants in Two Species of Antarctic Fish (Chionodraco Hamatus and Trematomus Bernacchii). Chemosphere 2008, 73, 155-160.

(33) Teil, M.-J.; Tlili, K.; Blanchard, M.; Chevreuil, M.; Alliot, F.; Labadie, P. Occurrence of Polybrominated Diphenyl Ethers, Polychlorinated Biphenyls, and Phthalates in Freshwater Fish from the Orge River (Ile-de France). Arch. Environ. Contam. Toxicol. 2012, 63, 101-113.

(34) Muir, D.; Sverko, E. Analytical Methods for PCBs and Organochlorine Pesticides in Environmental Monitoring and Surveillance: A Critical Appraisal. Anal. Bioanal. Chem. 2006, 386, 769-789.

(35) Hebert, C. E.; Keenleyside, K. A. To Normalize or Not to Normalize? Fat Is the Question. Environ. Toxicol. Chem. 1995, 14, 801-807.

(36) Powell, D. E.; Schøyen, M.; Øxnevad, S.; Gerhards, R.; Böhmer, T.; Koerner, M.; Durham, J.; Huff, D. W. Bioaccumulation and Trophic Transfer of Cyclic Volatile Methylsiloxanes (CVMS) in the Aquatic Marine Food Webs of the Oslofjord, Norway. Sci. Total Environ. 2018, 622-623, 127-139.

(37) Thomann, R. V. Bioaccumulation Model of Organic Chemical Distribution in Aquatic Food Chains. Environ. Sci. Technol. 1989, 23, 699-707.

(38) Arnot, J. A.; Gobas, F. A. P. C. A Food Web Bioaccumulation Model for Organic Chemicals in Aquatic Ecosystems. Environ. Toxicol. Chem. 2004, 23, 2343-2355.

(39) Ross, P. S.; Birnbaum, L. S. Integrated Human and Ecological Risk Assessment: A Case Study of Persistent Organic Pollutants (POPs) in Humans and Wildlife. Hum. Ecol. Risk Assess. Int. J. 2003, 9, 303-324.

(40) Benke, A. C.; Wallace, J. B. Trophic Basis of Production among Riverine Caddisflies: Implication for Food Web Analysis. Ecology 1997, 78, 1132-1145.

(41) Baumgärtner, D.; Rothhaupt, K.-O. Predictive Length-Dry Mass Regressions for Freshwater Invertebrates in a Pre-Alpine Lake Littoral. Int. Rev. Hydrobiol. 2003, 88, 453-463.

(42) Benke, A. C.; Huryn, A. D.; Smock, L. A.; Wallace, J. B. LengthMass Relationships for Freshwater Macroinvertebrates in North America with Particular Reference to the Southeastern United States. J. North Am. Benthol. Soc. 1999, 18, 308-343.

(43) Waters, T. F. Secondary Production in Inland Waters. Adv. Ecol. Res. 1977, 10, 91-164.

(44) Mills, C. A.; Mann, R. H. K. The Bullhead Cottus Gobio, a Versatile and Successful Fish. 51st Annual Report of the Freshwater Biological Association; Freshwater Biological Association: Ambleside, U.K., 1983; pp 76-88.

(45) Martinez, N. D. Artifacts or Attributes? Effects of Resolution on the Little Rock Lake Food Web. Ecol. Monogr. 1991, 61, 367-392.

(46) R Core Team. R: A Languages and Environment for Statistical Computing; R Foundation for Statistical Computing: Vienna, Austria, 2015

(47) Zuur, A. F.; Ieno, E. N.; Elphick, C. S. A Protocol for Data Exploration to Avoid Common Statistical Problems. Methods Ecol. Evol. 2010, 1, 3-14.

(48) Nelder, J. A.; Baker, R. J. Generalized Linear Models. In Encyclopedia of Statistical Sciences; Kotz, S., Read, C. B., Balakrishnan, N., Vidakovic, B., Johnson, N. L., Eds.; John Wiley \& Sons, Inc.: New York, 2006, p 4

(49) Tachet, H.; Bournaud, P.; Usseglio-Polatera, P. Invertébrés d'Eau Douce, 2nd ed.; CNRS éditions: Paris, 2002.
(50) Chevene, F.; Doleadec, S.; Chessel, D. A Fuzzy Coding Approach for the Analysis of Long-Term Ecological Data. Freshwater Biol. 1994, 31, 295-309.

(51) Statzner, B.; Resh, V. H.; Roux, A. L. The Synthesis of LongTerm Ecological Research in the Context of Concurrently Developed Ecological Theory: Design of a Research Strategy for the Upper Rhône River and Its Floodplain. Freshwater Biol. 1994, 31, 253-263.

(52) Gutiérrez-Cánovas, C.; Sánchez-Fernández, D.; Velasco, J.; Millán, A.; Bonada, N. Similarity in the Difference: Changes in Community Functional Features along Natural and Anthropogenic Stress Gradients. Ecology 2015, 96, 2458-2466.

(53) Bartoń, K., MuMIn: Multi model Inference, R Package. version 1.42.1. https://cran.r-project.org/web/packages/MuMIn (accessed Jul 21, 2018)

(54) Zuur, A. F.; Leno, E. N.; Smith, G. M. Analysing Ecological Data; Springer: New York, USA, 2007.

(55) Thomas, R.; Lello, J.; Medeiros, R.; Pollard, A.; Seward, A.; Smith, J.; Vafidis, J.; Vaughan, I. Data Analysis with $R$ Statistical Software: A Guidebook for Scientists; Eco-Explore: Newport, U.K., 2015.

(56) Windsor, F. M., The Transfer and Effects of Xenobiotic Pollutants in Freshwater Ecosystems, Ph.D. Thesis; Cardiff University, 2019.

(57) Willmott, C.; Matsuura, K. Advantages of the Mean Absolute Error (MAE) over the Root Mean Square Error (RMSE) in Assessing Average Model Performance. Clim. Res. 2005, 30, 79-82.

(58) Sarkar, S. K.; Binelli, A.; Riva, C.; Parolini, M.; Chatterjee, M.; Bhattacharya, A. K.; Bhattacharya, B. D.; Satpathy, K. K. Organochlorine Pesticide Residues in Sediment Cores of Sunderban Wetland, Northeastern Part of Bay of Bengal, India, and Their Ecotoxicological Significance. Arch. Environ. Contam. Toxicol. 2008, 55, 358-371.

(59) Odum, W. E.; Drifmeyer, J. E. Sorption of Pollutants by Plant Detritus: A Review. Environ. Health Perspect. 1978, 27, 133-137.

(60) Wang, J.; Bi, Y.; Henkelmann, B.; Wang, Z.; Pfister, G.; Schramm, K.-W. Levels and distribution of polybrominated diphenyl ethers in Three Gorges Reservoir, China. Emerging Contam. 2017, 3, $40-45$.

(61) de Perre, C.; Trimble, A. J.; Maul, J. D.; Lydy, M. J. Ecological Bioavailability of Permethrin and $\mathrm{p}, \mathrm{P}^{\prime}$-DDT: Toxicity Depends on Type of Organic Matter Resource. Chemosphere 2014, 96, 67-73.

(62) Bartrons, M.; Catalan, J.; Penuelas, J. Spatial and Temporal Trends of Organic Pollutants in Vegetation from Remote and Rural Areas. Sci. Rep. 2016, 6, 25446.

(63) Siddiqi, M. A.; Laessig, R. H.; Reed, K. D. Polybrominated Diphenyl Ethers (PBDEs): New Pollutants-Old Diseases. Clin. Med. Res. 2003, 1, 281-290.

(64) Liu, Y.; Luo, X.-J.; Huang, L.-Q.; Yu, L.-H.; Mai, B.-X. Bioaccumulation of Persistent Halogenated Organic Pollutants in Insects: Common Alterations to the Pollutant Pattern for Different Insects during Metamorphosis. Environ. Sci. Technol. 2018, 52, 51455153.

(65) Zhang, Y.; Luo, X.-J.; Wu, J.-P.; Liu, J.; Wang, J.; Chen, S.-J.; Mai, B.-X. Contaminant Pattern and Bioaccumulation of Legacy and Emerging Organhalogen Pollutants in the Aquatic Biota from an EWaste Recycling Region in South China. Environ. Toxicol. Chem. 2010, 29, 852-859.

(66) Yu, M.; Luo, X.-J.; Wu, J.-P.; Chen, S.-J.; Mai, B.-X. Bioaccumulation and Trophic Transfer of Polybrominated Diphenyl Ethers (PBDEs) in Biota from the Pearl River Estuary, South China. Environ. Int. 2009, 35, 1090-1095.

(67) Coat, S.; Monti, D.; Legendre, P.; Bouchon, C.; Massat, F.; Lepoint, G. Organochlorine Pollution in Tropical Rivers (Guadeloupe): Role of Ecological Factors in Food Web Bioaccumulation. Environ. Pollut. 2011, 159, 1692-1701.

(68) Verrengia Guerrero, N. R.; Taylor, M. G.; Davies, N. A.; Lawrence, M. A. M.; Edwards, P. A.; Simkiss, K.; Wider, E. A. Evidence of Differences in the Biotransformation of Organic Contaminants in Three Species of Freshwater Invertebrates. Environ. Pollut. 2002, 117, 523-530. 
(69) Wong, C. S.; Mabury, S. A.; Whittle, D. M.; Backus, S. M.; Teixeira, C.; DeVault, D. S.; Bronte, C. R.; Muir, D. C. G. Organochlorine Compounds in Lake Superior: Chiral Polychlorinated Biphenyls and Biotransformation in the Aquatic Food Web. Environ. Sci. Technol. 2004, 38, 84-92.

(70) van Beusekom, O. C.; Eljarrat, E.; Barceló, D.; Koelmans, A. A. Dynamic Modeling of Food-Chain Accumulation of Brominated Flame Retardants in Fish from the Ebro River Basin, Spain. Environ. Toxicol. Chem. 2006, 25, 2553.

(71) Statzner, B.; Bêche, L. A. Can Biological Invertebrate Traits Resolve Effects of Multiple Stressors on Running Water Ecosystems? Freshwater Biol. 2010, 55, 80-119.

(72) Godfray, H. C. J.; Stephens, A. E. A.; Jepson, P. D.; Jobling, S.; Johnson, A. C.; Matthiessen, P.; Sumpter, J. P.; Tyler, C. R.; McLean, A. R. A Restatement of the Natural Science Evidence Base on the Effects of Endocrine Disrupting Chemicals on Wildlife. Proc. R. Soc. B 2019, 286, 20182416. 